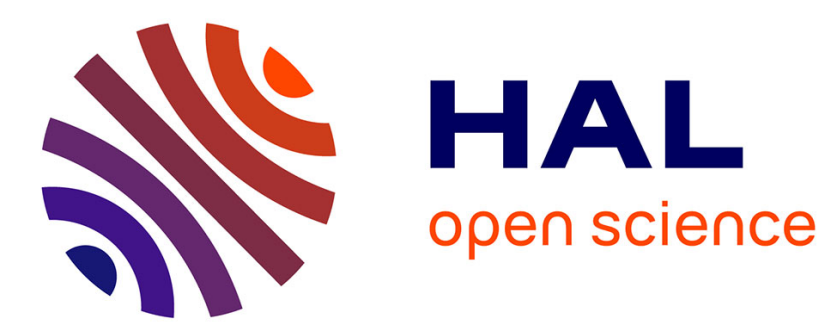

\title{
Interface properties in dielectrics: A cross-section analysis by atomic force microscopy
}

Christina Villeneuve-Faure, G. Teyssedre, Séverine Le Roy, Laurent Boudou, Kremena Makasheva

\section{To cite this version:}

Christina Villeneuve-Faure, G. Teyssedre, Séverine Le Roy, Laurent Boudou, Kremena Makasheva. Interface properties in dielectrics: A cross-section analysis by atomic force microscopy. 2018 12th International Conference on the Properties and Applications of Dielectric Materials (ICPADM), May 2018, Xi'an, China. pp.1135-1138, 10.1109/ICPADM.2018.8401246 . hal-02324432

\section{HAL Id: hal-02324432 \\ https://hal.science/hal-02324432}

Submitted on 1 Nov 2019

HAL is a multi-disciplinary open access archive for the deposit and dissemination of scientific research documents, whether they are published or not. The documents may come from teaching and research institutions in France or abroad, or from public or private research centers.
L'archive ouverte pluridisciplinaire $\mathbf{H A L}$, est destinée au dépôt et à la diffusion de documents scientifiques de niveau recherche, publiés ou non, émanant des établissements d'enseignement et de recherche français ou étrangers, des laboratoires publics ou privés. 


\title{
Interface Properties in Dielectrics: a Cross-section Analysis by Atomic Force Microscopy
}

\author{
C. Villeneuve-Faure, G. Teyssedre*, S. Le Roy, L. Boudou, K. Makasheva \\ Laplace, Université de Toulouse, CNRS, UPS, INPT, 118 route de Narbonne, F-31062 Toulouse Cedex 9, France
}

\begin{abstract}
Even if interfaces are more and more investigated their properties remain partially unknown, especially as regards their electronic properties. This is mainly related to the lack of characterization at relevant scale. In this context, electrical modes derivate from Atomic Force Microscopy appear well adapted. In this paper, a method to probe space charge at nanoscale is proposed. This method is based on surface potential measurement by Kelvin Probe Force Microscopy (KPFM) and post-processing technique based either on numerical derivation or Finite Element Method. Through these methods, densities of interface charges and injected charges were determined at different metal/dielectric interfaces.
\end{abstract}

\section{INTRODUCTION}

During the past decade physical phenomena at interface have been more and more investigated due to their strong impact on system performances [1]. However, a lot of mechanisms remain unknown as discrepancy between theoretical and experimental value of injection barrier [2]. The renewal of interest for interface processes is at least for two reasons in dielectrics: (i) the realization that processes controlling charge injection occur at atomic/nano scale and the disposal of ever more refined modelling approaches for accounting for the electronic properties at interfaces [3]; (ii) the input of nanomaterials in electrical engineering (as nanocomposites in high voltage insulations for example) [4] whereas the available characterization techniques are at microto macro-scale. Because of these challenges, scanning probe techniques are more and more used to characterize electronic properties of materials at sub-micrometric scale.

As far as dielectric materials are concerned, probing at nanoscale processes at interfaces between dielectric and electrode or in nanocomposite is crucial. Electrical modes derivate from Atomic Force Microscopy (AFM) such as Electric Force Microscopy (EFM) or Kelvin Probe Force Microscopy (KPFM) are ideal to probe free surface properties, a typical application being the charging of the surface using a biased AFM tip in 'writing mode', followed by probing electrostatic force or surface potential $[5,6]$. However, quantifying charges under these conditions is not straightforward, mainly because the behaviour of deposited charges is controlled both by surface and in-volume processes which are not included in electrostatic models [7].

To get information at small scale about processes at play in the volume, one possibility is to use lateral electrodes, which can be biased to inject charges, and to scan the inter-electrodes distance using AFM. One of the pioneering works is that proposed by Silveira et al. [8] dealing with charge injection in organic semiconductors as probed by EFM. Lambert et al. [9] investigated the transport of charges, under electric field, at the surface of $\mathrm{SiO}_{2}$ over few nm distances by EFM. Therefore the method can be used to monitor the injection of charges and their motion within the insulation at nanometer scales. However, the implementation of such methods is not straightforward and the building up of test structures is required to turn the methods adaptable to any insulation.

In this article, two methods to extract charge densities from surface potential measurement are proposed: one based on numerical derivation of surface potential and one based on Finite Element Method. These methods are applied to different samples to investigate interface related to the difference in work functions of the materials, and injected charges upon biasing the electrodes.

\section{EXPERIMENTS}

\section{A. Samples processing}

We consider herein results obtained with two kinds of samples, an inorganic thin layer and a polymer material realized with completely different processes.

The first one consists in 70nm-thick Al-electrodes embedded in $230 \mathrm{~nm}$-thick $\mathrm{SiN}_{\mathrm{x}}$ layer processed by Plasma Enhanced Chemical Vapor Deposition (PECVD). A thin $\mathrm{SiN}_{\mathrm{x}}$ layer is deposited over Al-electrode to passivate them. More detailed information is provided in reference [10]. The final structure is depicted on Fig.1.a.

The second structure consists in $45 \mu \mathrm{m}$-thick low density polyethylene (LDPE) film processed by hot-press molding using PE pellets. Then, a $200 \mathrm{~nm}$-thick $\mathrm{Cu}$ layer was evaporated on both sides to form $\mathrm{Cu} / \mathrm{LDPE} / \mathrm{Cu}$ structure. Cross-sections of the films were realized using ultra-cryomicrotome as depicted on Fig. 1.b.

\section{B. Measurement by KPFM and polarization step}
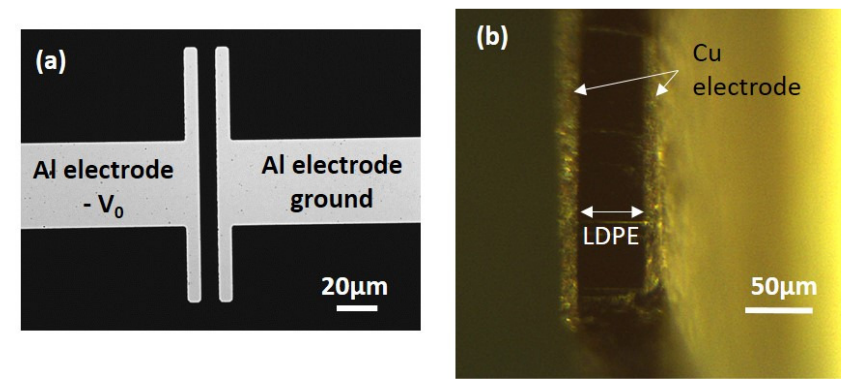

Fig. 1. Optical microscope pictures of (a) $\mathrm{Al}$ electrodes embedded in $\mathrm{SiN}_{\mathrm{x}}$ thin layer and (b) LDPE layer between $\mathrm{Cu}$-electrodes in cross-section. 
A Bruker Multimode 8 set-up and Pt-coated silicon tip where used to probe surface potential either in Amplitude (AM-KPFM) or Frequency (FM-KPFM) modes. For AMKPFM a $10 \mathrm{~nm}$ - lift height was used whereas FM-KPFM was performed in a single-pass. $\mathrm{SiN}_{\mathrm{X}} / \mathrm{Al}$ samples were conditioned for $4 \mathrm{~min}$ at $120^{\circ} \mathrm{C}$ before introduction in the environmental chamber (dry $\mathrm{N}_{2}$ atmosphere). The measurement step was fixed to $40 \mathrm{~nm}$. Measurements on LDPE samples were performed in the same dry environment without thermal preconditioning.

An electric field was applied to $\mathrm{SiN}_{\mathrm{x}} / \mathrm{Al}$ applying asymmetric bias on the electrodes for one hour (Fig. 1.a): ground on one electrode and $-\mathrm{V}_{0}$ on other one. The silicon substrate backside was set to the ground during the experiment. The surface potential was measured immediately after the polarization step.

\section{ChARGE DENSITY COMPUTATION}

To extract charge density from surface potential measurement two methods based on Poisson's equation solving, are available depending on the sample thickness.

\section{A. Second Derivative Method (SDM)}

The second derivative method (SDM) consists in a one dimensional (1D) model giving directly the charge density $\rho(x)$ as second derivative of the measured surface potential:

$$
\rho(x)=-\varepsilon_{0} \varepsilon_{r} \frac{d^{2} V_{S}}{d x^{2}}
$$

where $\varepsilon_{0}$ is the vacuum permittivity, $\varepsilon_{\mathrm{r}}$ the relative permittivity of the dielectric material, $\mathrm{V}_{\mathrm{S}}(\mathrm{x})$ the measured surface potential, and $x$ the lateral position.

This approach implicitly supposes that the measured potential is equivalent to that along the thickness direction in 1D with infinite planar geometry for the electrodes and the dielectric. So, the method is more adapted to thick dielectric layers. This method was already successfully exploited to extract charges density profile on $\mathrm{Al} / \mathrm{SiN}_{\mathrm{x}}$ [10] or $\mathrm{Al} / \mathrm{PEO}$ [11] samples.

(a)

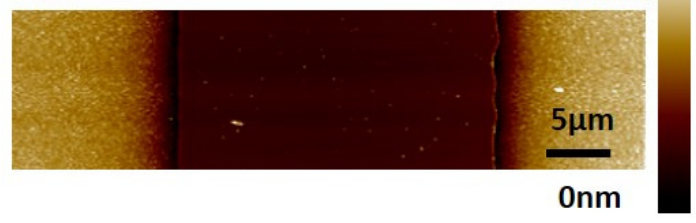

(b)

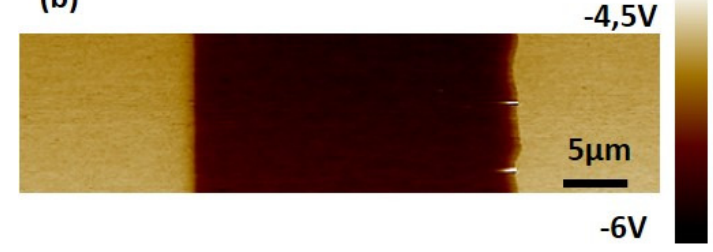

Fig. 2. (a) Topography and (b) surface potential map over Al/SiNx sample in FM-KPFM mode. Electrodes in cross-section.

\section{B. Finite Element Method (FEM)}

The Finite Element Model (FEM) is a two dimensional model which represents the real sample geometry (particularly its real thickness). The potential profile and the charge profile are computed using COMSOL Multiphysics ${ }^{\circledR}$ software. This model is composed by real sample geometry, surrounded by an air box of dimensions large enough to avoid edge effects. The silicon substrate backside is grounded and the electrodes remain at floating potential as in the experiment. The positive and negative charge density clouds are represented by Gaussian distributions:

$$
\rho(x)=\rho_{0} \exp \left(-\frac{\left(x-x_{0}\right)^{2}}{0.36 W^{2}}\right)
$$

where $\rho_{0}$ is the maximum charge density value (positive for holes and negative for electrons), $x_{0}$ is position maximum -i.e. the interface and $\mathrm{W}$ is the Full Width at Half-Maximum (FWHM) of the charge cloud. The Poisson's equation (Eq. 1) is solved in the dielectric layer and in the surrounding air to determine the potential distribution in the structure.

Charge density profile is determined comparing characteristics of experimental and computed surface potential profiles and iterating on the shape parameters of the Gauss curves for the charge distributions. The criterion to stop the iterations is on the minimization of the difference between experiment and modelling which correspond to the resolution of the technique [12]. The main advantages of this model are that is takes into account the real thickness of the dielectric layer and offers identification of the real extension of the charges cloud in the volume.

\section{RESULTS AND DISCUSSION}

\section{A. Interfaces characterization}

Fig. 2 compares the topography and surface potential map for the $\mathrm{Al} / \mathrm{SiN}_{\mathrm{x}}$ sample. Al electrode appears with higher surface potential than $\mathrm{SiN}_{\mathrm{x}}$. Moreover, from topography and surface potential point of view, the interface appears steep, but in reality the width is significant. As shown on Fig. 3, the transition between $\mathrm{Al}$ and $\mathrm{SiN}_{\mathrm{x}}$ surface potential occurs over about $1.5 \mu \mathrm{m}$ which is larger than the typical KPFM resolution on flat surface. The transition width could be due to parasitic

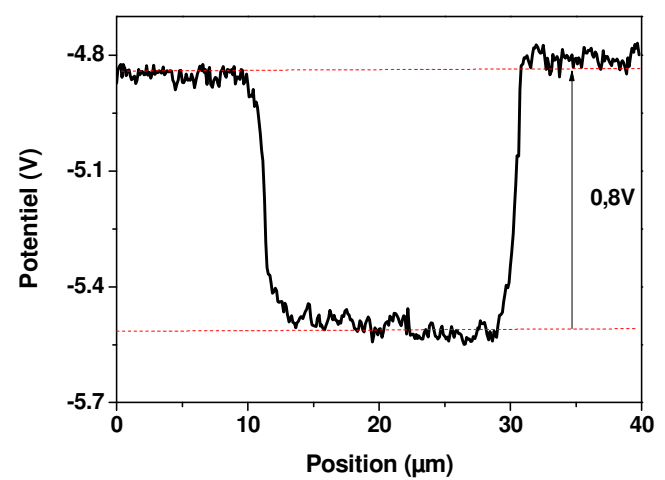

Fig. 3. Surface potential profile between electrodes measured on $\mathrm{Al} / \mathrm{SiNx}$ sample by FM-KPFM 
capacitance induced by topography modifications close to the interface.

Fig. 4 compares the topography and surface potential maps for $\mathrm{Cu} / \mathrm{LDPE} / \mathrm{Cu}$ structure. From topography point of view, the interface between $\mathrm{Cu}$ and LDPE is difficult to see due to low contrast. However, as shown on Fig.5a, topography profile shows that interface is steep. Contrary to topography, the surface potential decreases slowly from the interface to the LDPE bulk. Indeed, as shown on Fig. 5a, the surface potential profile exhibits a "bell-like" shape with transition width over around $20 \mu \mathrm{m}$. This effect could not be attributed to KPFM artefacts but rather to electrical charge accumulation close to the interface which induces a smooth surface potential evolution along the depth.

\section{B. Computation of charge profile}

To verify this hypothesis, the SDM method was applied to extract charge density profiles from the surface potential profiles. In this case pixel size and derivation step $\mathrm{dx}$ are equal to $140 \mathrm{~nm}$. Moreover, derivation was done only in the LDPE layer considering that the dielectric permittivity is constant $\left(\varepsilon_{\mathrm{r}}\right.$ $=2.2$ ). Otherwise, Eq. 1 should be revisited to account for the space-dependent permittivity. The charge density profile after double-derivation of the potential profile is shown in Fig. 5b. According to the analysis, positive charge clouds would be present close to both interfaces and extend over around $2 \mu \mathrm{m}$. A maximum charge density of $60 \mathrm{C} / \mathrm{m}^{3}$ is obtained. The charge integrated over the region close to the interface corresponds to a surface charge density of $1.2 \times 10^{-4} \mathrm{C} / \mathrm{m}^{2}$.

The charge exchanges processes when $\mathrm{Cu}$ or $\mathrm{Au}$ crystals are put in contact with LDPE were modeled using DFT [13]. It was shown that, in both cases, the LDPE donates electrons to the adjacent metal, i.e. the charge at the contact tends to be positive for LDPE. According to the DFT model [13], the extent of the charge cloud is extremely small, about $0.2 \mathrm{~nm}$, and the surface density very high, about $2 \times 10^{-2} \mathrm{C} / \mathrm{m}^{2}$. Owing to the huge charge density it represents and hence large field variation $\left(\approx 10^{9} \mathrm{~V} / \mathrm{m}\right)$, the polymer would certainly relax. Because of the natural roughness of the interface, the charge profile measured experimentally would evidently spread over larger distances. In addition, the spatial resolution of the KPFM (around $10 \mathrm{~nm}$ in air environment) and the possible further distortion due to topography step at the electrodes (cf. Fig. 5a) make broader the spatial distribution of charge determined experimentally.

The present results tend to show that even without applied voltage, charges may build up at the interface of dielectrics. The shape of the curve shown here has grossly the same features when dealing with LDPE associated with semiconducting electrodes made of carbon black doped polymer [14]. The sign of the charges is consistent with that predicted by DFT; the amount of charge and shape of the profile are not. This can be explained in part by the real conditions which are far away from the idealized ones in DFT. The reasons as why in some dielectrics the voltage profiles are sharp at the interface with metal and in some others they are steeper is worth elucidating. The spread of the contact charge

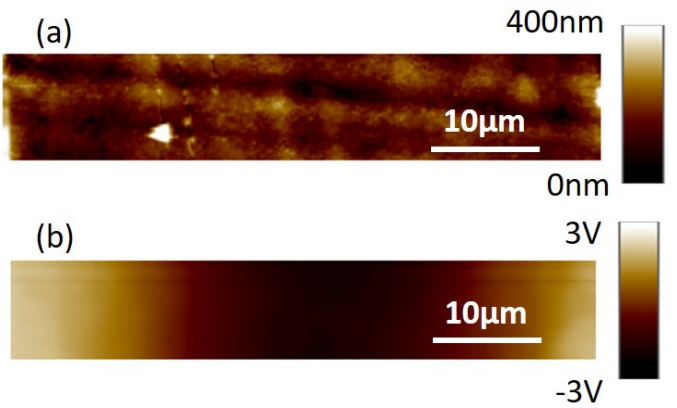

Fig. 4. (a) Topography and (b) surface potential map over on Cu/LDPE sample in AM-KPFM mode.

over larger distances then the expected ones can be a reason. Another possibility is the compensation of the charges by other carriers that would provide more neutral states.

\section{Charge injection at Al/SiN interface $^{-}$}

Let's consider now how the surface potential profiles evolve after basing the electrodes. Fig 6a presents surface potential profiles after $\mathrm{Al} / \mathrm{SiN}_{\mathrm{x}} / \mathrm{Al}$ sample polarization under different voltages. Whatever the polarization voltage, two peaks appear close to the metal/dielectric interfaces; a negative peak close to the cathode and a positive peak close to the anode side. The peak amplitude increases with applied voltage (i.e. with the electric field increase). The potential
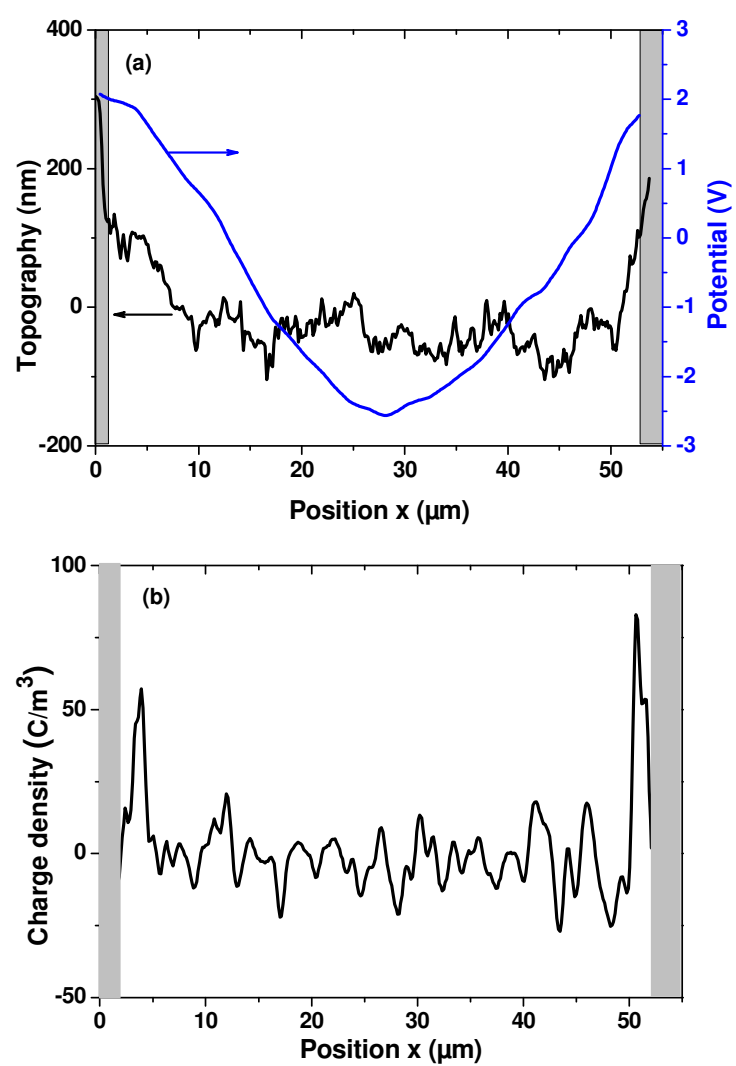

Fig. 5. (a) Comparison of topography and surface potential profile between electrodes measured on Cu/LDPE sample by AM-KPFM. (b) Charge density profile in LDPE determined using SDM. 

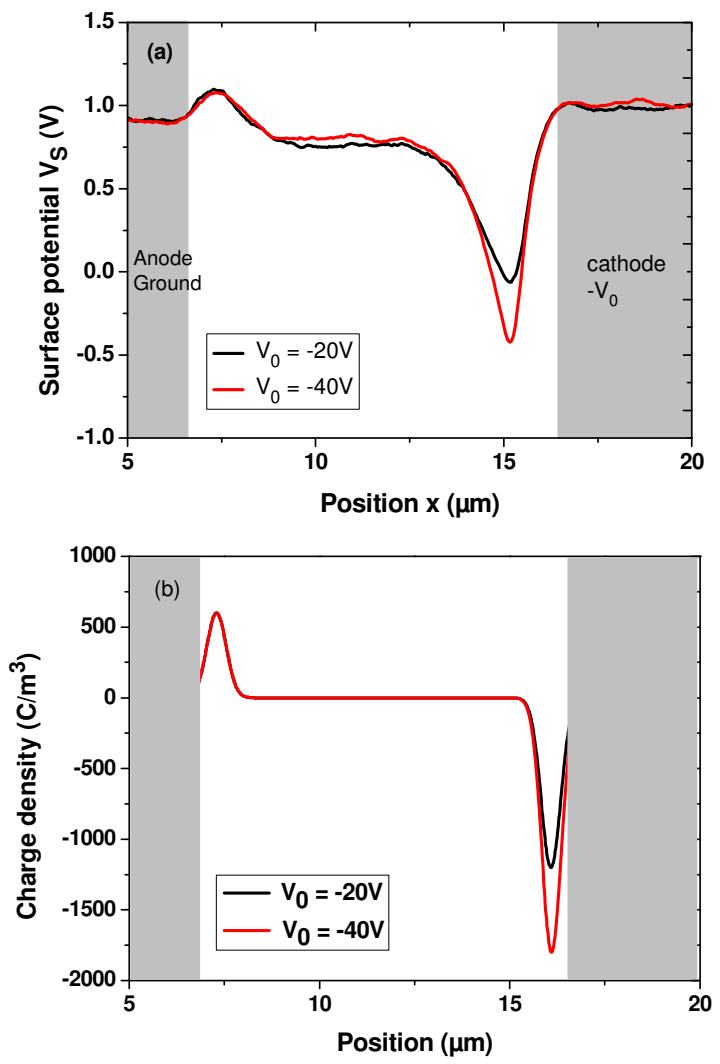

Fig. 6. (a) Surface potential profile after polarization during $1 \mathrm{~h}$ (ground applied on left electrode and $-20 \mathrm{~V}$ or $-40 \mathrm{~V}$ applied on right one). The backside of the sample is to the ground. (b) Charge density profile after polarization computed using FEM method.

profile prior to polarization was as in Fig. 6.a, i.e. negative, with $\Delta \mathrm{V} \approx-0.2 \mathrm{~V}$ in the $\mathrm{SiN}_{\mathrm{x}}$ layer in respect to the passivated $\mathrm{Al}$ electrodes.

Fig. 6b shows the charge density profiles determined using the FEM model (the dielectric permittivity of the $\operatorname{SiN}_{\mathrm{x}}$ layer is taken $\varepsilon_{\mathrm{r}}=7.5$ ). The charge generated at the cathode is clearly larger and more voltage dependent compared to the situation at the anode. The result can be explained by the fact that the substrate beneath the $230 \mathrm{~nm}$ thick $\mathrm{SiN}_{\mathrm{x}}$ layer is grounded. As a consequence, the modulus of the electric field at the anode is lower during charging and the amount of generated charges is less. A 2D model, $E(x, z)$ has to be considered for this case of relatively thin layers. This further substantiates the need to compute the charge profile by using the FEM approach.

\section{CONCLUSION}

Different methodologies to extract charge density from surface potential measurements by KPFM have been exploited to probe the contact charges as well as charges generated under biased electrodes. Without any applied bias, the KPFM voltage profiles at $\mathrm{LDPE} / \mathrm{Cu}$ interface exhibit a smooth potential variation which has been turned into interface charge using second order derivation. The observed features appear to be related to the build-up of contact charges probably spreading into the insulation. In the case of $300 \mathrm{~nm}$-thick $\mathrm{SiN}_{\mathrm{x}}$ dielectric with embedded $\mathrm{Al}$ electrodes, the KPFM profiles are much steeper. In these structures, positive and negative charges can be generated under DC stress. Due to the geometry of the system, the field at the electrodes is distorted in respect to the inter-electrode gradient. FEM modelling is then necessary to properly extract the charge distribution.

Though potentially many variants of the KPFM method can be designed, the relevance of the obtained results requires a rigorous treatment of the electrostatic problem.

\section{ACKNOWLEDGEMENT}

We thank the French network GDR-SEEDS for support to part of this study.

\section{REFERENCES}

[1] P. Morshuis "Interfaces: to be avoided or to be treasured?" Proc; IEEE International Conference on Solid Dielectrics, Bologna, Italy, 2013.

[2] L. Chen, T.D. Huan, Y. Cardona Quintero and R. Ramprasad "Charge injection barriers at metal/polyethylene interfaces" J. Mater. Sci., Vol. 51, p.506, 2016.

[3] L. Chen, T.D. Huan, and R. Ramprasad, "Electronic structure of polyethylene: Role of chemical, morphological and interfacial complexity", Scientific Reports, Vol. 7, p.6128, 2017.

[4] I. Plesa, P.V. Notingher, S. Schlogl, C. Sumereder and M. Muhr "Properties of polymer composites used in high-voltage applications", Polymers, Vol. 8, p.173, 2016.

[5] M. Ishii "Static states and dynamic behavior of charges: observation and control by scanning probe microscopy", J. Phys.: Cond. Matter, Vol. 22, p.173001, 2010.

[6] C.A. Rezende, R.F. Gouveia, M.A. da Silva and F. Galembeck "Detection of charge distributions in insulator surfaces", J. Phys.: Condens. Matter, Vol. 21, p.263002, 2009.

[7] E. Pallau, L. Ressier, L. Borowik and T. Melin "Numerical simulations for a quantitative analysis of AFM electrostatic nanopatterning on PMMA by Kelvin force microscopy", Nanotechnology, Vol. 21, p.225706, 2010.

[8] W.R. Silveira and J.A. Marohn, "Microscopic view of charge injection in an organic semiconductor", Phys. Rev. Lett., Vol. 93, p.116104, 2004.

[9] J. Lambert, G. de Loubens, C. Guthmann and M. Saint-Jean, "Dispersive charge transport along the surface of an insulating layer observed by electrostatic force microscopy", Phys. Rev. B, Vol. 71, p.155418, 2005.

[10] C. Villeneuve-Faure, L. Boudou, K. Makasheva and G. Teyssedre "Methodology for extraction of space charge density profiles at nanoscale from Kelvin Probe Force Microscopy measurements" Nanotechnology, Vol. 28, p.505701, 2017.

[11] K. Faliya, H. Kliem and J.C. Dias "Space charge measurements with Kelvin Probe Force Microscopy”, IEEE Trans. Dielec. Electr. Insul., Vol. 24, p.1913, 2017.

[12] C. Villeneuve-Faure, L. Boudou, K. Makasheva and G. Teyssedre "Atomic force microscopy developments for probing space charge at sub micrometer scale in thin dielectric films", IEEE Trans. Dielec. Electr. Insul., Vol. 23, p.713, 2016.

[13] S. Le Roy, C. Villeneuve-Faure, J.H. Chang, and A. Huzayyin, "Coupling molecular modeling, fluid modeling, and KPFM measurements to characterize an interface at nanoscale", Proc. IEEE International Conference on Dielectrics (ICD), Montpellier, France, p.897, 2016.

[14] F. Gullo, T. Christen, C. Villeneuve-Faure, C. Törnkvist, S. Le Roy, H. Hillborg, C. Laurent and G. Teyssedre, "Nano-scale characterization of dielectric-semicon contacts", Proc. IEEE International Conference on Dielectrics (ICD), Montpellier, France, p.796, 2016. 